\title{
A Wild Animal Inside My House: An Analysis of the Children's Picturebook Svenn the Otter and the Magic Rock by Espen Villseth and Anita Sletten
}

\author{
Nahúm M. Tórrez \\ Department of Language and Literature, University of South-Eastern Norway, Horten, Norway; \\ Tranby Middle School, Lier, Norway \\ Marjorie N. Gómez \\ Department of Language and Literature, Universidad Nacional Autonóma de Nicaragua, Estelí, Nicaragua
}

\begin{abstract}
Svenn, a wild otter, has become an Instagram celebrity with over 140,000 followers around the world. Svenn has his own YouTube channel and Facebook page. Moreover, in December 2020, NRK, an influential Norwegian TV channel, released a series entitled "Oteren Svenn" (Svenn, the Otter), consisting of ten episodes. In addition to all of this, Svenn has his own picturebook for children, which is entitled Svenn the Otter and the Magic Rock (Villseth \& Sletten, 2020). This article presents the picturebook and analyzes three of its significant spreads. The aim is to uncover aspects of the sociocultural context in which Svenn - along with other characters - is portrayed by images and verbal language in the book, and to provide a short discussion of how the book may be used in English Language Teaching (ELT). Our analysis builds on tools from multimodal text analysis (Kress \& van Leeuwen, 2005; van Leeuwen, 2005) and Narrative Intelligence (Mateas \& Senger, 2003). The analysis focuses on the significance of the picturebook to represent participants in actions, the relationship between the book's participants and the reader, and the value of presenting images and verbal text together. Our analysis also touches on some implications for ELT, on the potential that visual literacy can have in language teaching.
\end{abstract}

Index Terms-children's picture books, Svenn, the otter, English Language Teaching (ELT), multimodality

\section{INTRODUCTION}

Svenn has become an Instagram celebrity with over 140,000 followers around the world. Svenn has his own YouTube channel and Facebook page. Moreover, in December 2020, NRK, an influential Norwegian TV channel, released a series entitled "Oteren Svenn" (Svenn, the Otter), consisting of ten episodes. In addition to all this, Svenn has his own picturebook for children, entitled Svenn the Otter and the Magic Rock (Villseth \& Sletten, 2020).

The aforementioned statements demonstrate how increasingly interconnected the world is through different resources. We are currently interacting with a wider range of communication practices: videos that can be edited and posted on the Internet or documents that can be sent in seconds or shared simultaneously (Freire, 2020). We are also constantly overwhelmed with new textual genres (e.g., blogs, pop-up ads). Moreover, we have technological resources that allow us to choose more easily between ways of meaning making (e.g., posting a photo of a scene rather than describing it verbally) (Fuchs, Hauck, \& Müller-Hartmann, 2012). Based on these observations, we highlight the increasing role that images are taking on in different spaces (e.g., education), in comparison to - and alongside - verbal language, in a wide diversity of texts in our daily lives.

Texts or printed works have shaped different aspects of society since human beings began to manifest their reality by manipulating linguistic signs in order to record moments, stories, or creations (Lehtonen, 2000). Texts, marked by the development of languages around the world and the socio-cultural expansion of their different variations, are vast and mixed. Therefore, it is not wrong to consider texts as part of cultures, products of different contexts based on social interaction and supported by communities that enable the development of languages in their different manifestations (e.g., visual, semiotic). As Lehtonen (2000) points out, human beings embody some kind of social spoken and unspoken language. For instance, visual literacy, which can be understood as the active process of reading, interpreting and understanding images and visual media, has been developed in compelling ways in different educational subjects in education; for example, in English (Stafford, 2010). One of the values of visual literacy is its link to the act of storytelling, which helps us to better understand concepts such as plots, themes or narratives.

In this article, we present the children's picturebook Svenn the Otter and the Magic Rock and analyze a group of three significant spreads. Our aim is to analyze aspects of the sociocultural context in which Svenn - along with other 
characters - is portrayed by images and verbal language in the book. Moreover, we provide a short discussion of how the book may be used in English Language Teaching (ELT). An important goal of this paper is to present a readerfriendly and practical discussion for ELT classroom teachers in Norway and beyond. As Svenn has gone viral around the world, and the resources mentioned earlier are available everywhere, we argue that our discussion can be useful for teachers in different learning contexts. This article also aims to illuminate how storytelling brings language and other meaning-making resources together to convey traces of people's cultural and linguistic contexts through the power of narratives. The specific objective of this paper is to describe and analyze the possible nature and function of picturebooks and, mainly, to highlight the multimodality of storytelling in ELT and how narratives in storytelling are configured to accomplish both sociocultural and social semiotic purposes.

In relation to the picturebook, the Norwegian author Espen Villseth wrote the verbal text, and the Norwegian artist Anita Sletten illustrated the book. The picturebook was originally published in both Norwegian and English; this article examines the English version. The picturebook is addressed to children ages two to five. However, according to the publishing house Nordic Wild, older children, teenagers and adults may also enjoy reading the book.

The picturebook was published in November 2020. It tells the story of Svenn, the otter, who has a magic rock that can talk. In the book, we are also introduced to Pernille, a pug dog. Apart from Svenn and Pernille, no one knows that Svenn's rock can talk. Two children are also part of the story. Their names are Isak and Iselin. One day, Svenn wakes up with a lump in his stomach; the magic rock is missing. Faced with this situation, Svenn and Pernille embark on a mission to find their missing friend, the rock.

\section{PREVious ReseARCH}

Despite the growing interest in multimodality in international scholarly research, multimodality has received little attention in relation to ELT in Norway (Maagerø \& Tønnessen, 2014). Skulstad (2018) has analyzed textbook tasks, calling for a new understanding of communicative competence that includes multimodality. In English language education, communicative competence ought to be focused on the speaker's social performance in terms of language use, using various resources such as discourse, images or texts (Gomez, 2020). In relation to cultural representation, Lund (2016) and Waallann-Brown and Habegger-Conti (2017) have investigated textbook images, finding a tendency to stereotype indigenous peoples as primitive. In terms of assessment, Jakobsen (2019) has examined the role of multimodality in assessment practices, finding that multimodal preparation material and well-designed examinations can help students understand the content of such assessment material better.

In terms of language teaching, the field has been altered due to transmutations with regard to the concept of language, as language is less and less interpreted as an immovable autonomous system. With the interaction of people using different resources for communication, the sociocultural use of language is in a constant state of evaluation and transformation (Gomez, 2020). Traditionally, oral and written speech continues to be essential in any situation of social communication. However, the abilities and the knowledge that characterize the person as a good communicator, in any given language, have been influenced by the variety of multimodal resources (e.g., images, text) available to the person (Donaghy \& Xerri, 2017). In this new multimodal scenery, education ought to be changed, methodologies reevaluated, and new digital and physical resources included. It can be argued, then, that the development of appropriate abilities by way of multimodal resources in the teaching-learning process needs to be discussed and evaluated. A good starting point for discussion would be children's multimodal learning resources.

With respect to Norwegian research on children's picturebooks from a multimodal perspective, Maager $\varnothing$ and Øines (2019) have analyzed one picturebook that deals with how to make a baby. Maager $\varnothing$ and Lørentzen (2017) have analyzed issues of liberation, i.e., a girl fighting for freedom and self-esteem. They have also analyzed a picturebook in which issues of existential topics such as life and death, growing up and growing old, God, and children's relationship to nature are discussed. Our work with the picturebook Svenn the Otter and the Magic Rock follows in a similar vein as the last-mentioned analysis. That is, we examine the relationship between nature and children in the picturebook, understanding the social context, at least to some extent. However, our work is also aimed at adding to the discussion of the relevance of picturebooks applied to ELT.

We set out to answer the following research questions:

1. How is the otter Svenn portrayed by images and verbal language in the children's picturebook, and what insights can be gained from the social context in which he is depicted?

2. How can this children's picturebook be used in ELT, when working with understanding events and retelling stories from different perspectives?

In the following sections, we first present our theoretical and analytical framework. Second, we provide a summary of the categories which guide our analysis. Third, we analyze three significant spreads. Finally, we discuss our findings and conclude the article with some limitations and suggestions for further research.

\section{THEORETICAL AND ANALYTICAL FRAMEWORK}

The analysis of the children's picturebook Svenn the Otter and the Magic Rock builds on the theory of multimodality (Kress \& van Leeuwen, 2006), which is anchored in a social semiotic approach to language and communication 
(Halliday \& Hasan, 1989; van Leeuwen, 2005). In a general sense, multimodality focuses on the way people draw on distinctly different sets of resources for making meaning (Jewitt, Bezemer \& O'Halloran, 2016). The term "multimodal texts" is used to refer to texts that create meaning from several semiotic resources such as images, speech, writing, sound, color, etc. (see also Kress \& van Leeuwen, 2006). Today's picturebooks consist mainly of colorful pictures and verbal text. Some books feature supplementary materials such as audio files, which attempt to grab the learner's attention more easily. In this way, picturebooks may contribute to language learning through the interaction of multiple modes.

Our work builds on the theory of the metafunctions (Halliday, 1978) and we also use Kress and van Leeuwen's (2006) work with visual analysis. More specifically, we use the categories representation and interaction in order to shed light on how Svenn - along with other characters - is depicted in the book. We also use notions of multimodal orchestration, as suggested by van Leeuwen (2005), in order to examine how images and verbal text together contribute to making depictions of Svenn in the book. Additionally, we draw on studies related to the use of picturebooks and visual literacy in education, and on Narrative Intelligence (Mateas \& Senger, 2003) in order to link our analysis to ELT.

For reasons of space and the nature of our paper, we will make an analysis of three spreads from the book. The spreads were provided by the author and illustrator to analyze main categories. Both visual and verbal language from the spreads make it possible to build narrative representations of the world, assigning roles to represent participants people, objects, institutions, and to establish different relationships between participants in the text, as well as between them and the reader.

\section{A. Visual Literacy and ELT}

The inclusion of picturebooks in English language education has been addressed for more than four decades. However, research has shown a lack of diversity (e.g., minority groups) in books published for children (Koss, 2015). Arguably, books should reflect the social and cultural contexts of different populations in addition to standard literacy elements. Also, picturebooks ought to move away from graded materials in language teaching to more authentic ones (Mourão, 2017). Scholars, such as the aforementioned, have observed that picturebooks have the potential to provide an educational framework to help children understand different features of the target language, such as social, cultural, and linguistic aspects. They also have the potential to assist children's development as a whole, in the language education realm (Ellis \& Brewster, 2014). One of the significant values of picturebooks can be seen in the use of storytelling in the education system across cultures. Research suggests that storytelling provides a context that can easily assist in the interpretation of the human experience, such as struggles we face with others or with nature, and also to teach cultural values in a natural way (Lucarevschi, 2016). Readers get emotionally engaged with the story as they see themselves and others reflected in the story. Certainly, stories bring experiences to life and we organize those experiences in the form of narratives.

\section{B. Narrative Intelligence}

Narrative intelligence (NI) was born as a study group in 1990, where some scholars gathered from MIT (Massachusetts Institute of Technology, USA) Media Laboratory to discuss core ideas from philosophy, media theory and psychology, combined with research in computational theories. The main goal behind the creation of this discussion group was to understand the human use of narratives to make meaning of the world, using a variety of interdisciplinary ideas (Mateas \& Senger, 2003). At that time, such an approach involved novel ways of thinking about narratives and their function in the human experience of the world. Over the years, NI has crossed disciplinary boundaries and it has influenced other areas of knowledge, for example, in literature studies. In NI, three main ideas have usually been discussed: "representation", "language", and "communication".

In storytelling, the simplest definition of narrative intelligence is the ability to convey and understand the story. This ability can have significant implications in language education, as a story can be a means to uphold the life experience of some cultures, especially those communities that have used storytelling to affirm their own culture (Pishghadam, Golparvar, Khajavi, \& Iranrad, 2011). In ELT, a number of studies about the use of textbooks in schools have revealed biases favoring certain cultural groups over others; for instance, American and British culture (Song, 2013). Therefore, NI in ELT can be useful not only to develop cognitive abilities (i.e., long-term memory, visual processing) but also to represent students' own local culture through narratives in storytelling (Pishghadam, Golparvar, Khajavi, \& Iranrad, 2011).

Based on the previous discussion; the following sections present the categories, within multimodality, which serve as a baseline for our analysis.

1. Representation

In the verbal mode, actions and events are usually registered using verbs (Halliday \& Hasan, 1985). In the visual mode, the analysis of representation starts by identifying the people (hereafter "participants"), places, and things depicted in an image. This representation can be both abstract and concrete. Next, it looks at events and the actions carried out by the represented participants, and at their attributes and qualities. Kress and van Leeuwen (2006) talk about two types of visual representations; namely, narrative and conceptual representation. The former is characterized by the presence of vectors or eyelines, which connect the represented participants as doing something to or for one another. In other words, narrative representations depict the participants in terms of their actions and the events in the 
story. The latter is characterized by the lack of vectors or eyelines, and this type of representation portrays the participants in terms of their qualities and attributes. Conceptual representations depict the participants in their generalized essence.

\section{Interaction}

In the verbal mode, sentences can make an invitation to interaction or require a response (Halliday \& Hasan, 1985). In the visual mode, the analysis of interaction deals with the relationship created between the represented participants and the viewer of the text. Kress and van Leeuwen (2006) refer to two ways of interaction in the visual mode. They talk about demands and offers. In the former, the represented participants typically gaze at the viewer. This gaze creates a vector between the eyeline of the represented participant and the viewer, demanding a response of some kind. In the latter, on the other hand, the represented participants do not look directly at the viewer but gaze away. Here, the represented participants make indirect contact only, being offered as objects for the viewer's contemplation.

\section{Multimodal Orchestration}

Pictures are only half of the story when it comes to most picturebooks (Painter, Martin \& Unsworth, 2013). One can thus also argue that the verbal language is only half of the story. In order to analyze the interplay between images and verbal language in the book under scrutiny, we build on van Leeuwen's notion of multimodal orchestration (van Leeuwen, 2005). Van Leeuwen's work includes several categories and sub-categories. However, in order to limit our analysis, we build on two specific categories: elaboration and extension. In the case of elaboration, one modality repeats or restates information for clarification. In the case of extension, on the other hand, one modality adds new information, linking it to the existing one (van Leeuwen, 2005, p. 222).

\section{MAterials AND Methods}

The research material consists of the aforementioned children's picturebook entitled Svenn the Otter and the Magic Rock (Villseth \& Sletten, 2020). We have chosen to look closely at three significant spreads. The rationale behind the choice of these three spreads is that they all depict Svenn's encounter with a new environment. One of the spreads depicts Svenn in relation to Pernille and the two children (Isak and Iseline), and two spreads depict him in relation to his new physical home. The three spreads are the following ${ }^{1}$ :

- $\quad$ Spread 6 - The relationship created between Svenn and the children (pp. 14,15)

- Spread 9 - Svenn's encounter with a flower vase and a pink basin (pp. 20,21)

- $\quad$ Spread 11 - Svenn's encounter with the toilet (pp. 24)

As mentioned above, our analysis builds on the work of Kress and van Leeuwen (2006) with visual analysis. More specifically, we draw on the categories of representation and interaction. Additionally, we use notions of multimodal orchestration, as suggested by van Leeuwen (2005), in order to analyze how images and verbal language together contribute to creating the depictions in the book. For the sake of simplicity, we chose to analyze multimodal orchestration in relation to all three of the spreads as one unit, after analyzing the three spreads in terms of the first two categories (representation and interaction). This choice is supported by the fact that the same tendencies are found in the three spreads, as elaborated later in the text. The following table provides an overview of the elements examined in the selected spreads:

TABLE 1

THE ELEMENTS EXAMINED

\begin{tabular}{|l|l|l|}
\hline Category & Sub-category & Element examined \\
\hline Representation & $\begin{array}{l}\text { Narrative vs conceptual } \\
\text { representations }\end{array}$ & $\begin{array}{l}\text { The people, places and things depicted by narratives. } \\
\text { The presence of vectors, depicting actions and reactions. }\end{array}$ \\
\hline Interaction & Demands and offers & $\begin{array}{l}\text { The presence of gaze from the represented participants towards the } \\
\text { viewer. }\end{array}$ \\
\hline Multimodal orchestration & $\begin{array}{l}\text { Elaboration } \\
\text { Extension }\end{array}$ & $\begin{array}{l}\text { Elaboration: One modality repeats or restates information for } \\
\text { clarifications. } \\
\text { Extension: One modality adds new information, linking it to the } \\
\text { existing information. }\end{array}$ \\
\hline
\end{tabular}

We emphasize that picturebooks can be analyzed in different ways and that the present analysis presents one way only. Moreover, we find it important to clarify that we do not make a systematic and detailed analysis of the verbal language present in the spreads. Our focus is mainly on the images, but we also look at how the verbal language (e.g., text) contributes to depicting Svenn, along with other characters in the book.

\footnotetext{
${ }^{1}$ We find it important to mention that the page number of the spreads provided by the illustrator do not match the page number on the printed book.
} 


\section{ANALYSIS OF SignifiCANT SPREADS}

Spread 6 - The relationship created between Svenn and the Children
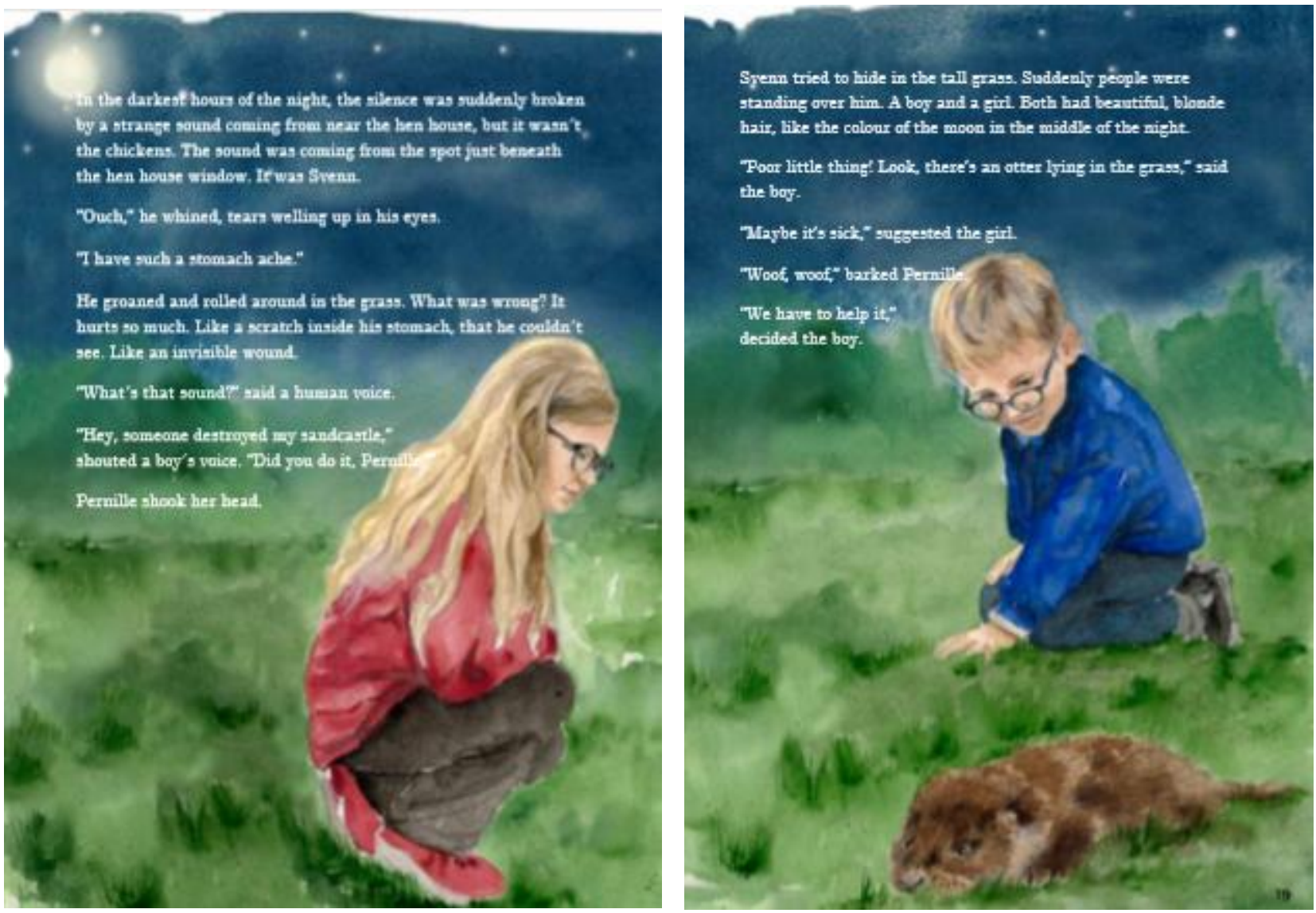

As our main goal is to analyze the sociocultural environments in which Svenn is depicted, it was natural to examine spreads which depict him both alone and/or in the company of the two children and Pernilla, the dog. In this regard, the relationship created between the otter Svenn and the children is a very interesting issue, as it encompasses a multiplicity of narratives, involving modes of representation that vary according to the specific culture and context. Again, our analysis looks at the ways in which the characters are represented, the interaction which is created between them and the reader, and at the way images and the verbal text interact in order to depict the main characters in a way that goes beyond just the linguistic representation.

\section{Representation}

In spread six, all four characters are portrayed together: Svenn, the two children, and Pernille. The two children are focusing their attention on Svenn, who seems to be looking for something. This is a narrative representation, as vectors are formed from the children's gaze towards Svenn. Similarly, Svenn seems to be moving as his head and nose are directed towards the grass. It is important to note the background of the spread. On the upper left-hand side, we see the moon. On the whole upper part of the spread, we also see stars. This is an indication of the time of day when the event takes place, namely, nighttime. This fact is confirmed by the verbal text in the spread: "In the darkest hours of the night". This statement can be interpreted as an indication of urgency, something that cannot wait and needs to be done.

As mentioned above, Svenn seems to be looking for something. At this point, the verbal text does not tell us what Svenn is looking for. However, it does describe Svenn's feelings and emotions by disclosing that Svenn has a stomachache, that he whines with tears welling up in his eyes, and that he tries to hide in the tall grass when he sees humans approaching him (Villseth \& Sletten, 2020, p. 14). It also describes the children's attitude towards Svenn when they first see him: "Poor little thing! Look, there's an otter lying in the grass", "Maybe he's sick", "We have to help him" (Villseth \& Sletten, 2020, p. 15). The verbal text in this spread also tells us that Pernilla is present in the event: "Woof, woof, barked Pernille". However, she is not visually depicted in the image.

In sum, both the images and verbal text depict Svenn as a fearful and sad animal in this spread, and the children as kind, caring and loving humans. Again, Pernille is not present in the image, but one can imply that she is helping Svenn look for what it is missing. Thus, she is also presented as a friend in the spread. Moreover, the contextual elements in the image (e.g., the moon and stars) together with the phrase "in the darkest hours of the night", creates tension and a sense of urgency. 
In other words, in order to represent the experience of participants in this spread, images are both narrative and conceptual. Narrative representations build experience as an event that unfolds in space and time; that is, they portray the participants through the actions they perform related to other participants or through the events that they are involved in. The conceptual representations describe or classify the participants in the image in terms of their individual characteristics, evidencing their identity as part of their culture or those traits shared with other participants, which allow us to perceive them as members of a group.

Interaction

In terms of interaction, the sixth spread offers a revealing image to the viewer. There is no gaze between the represented participants and the viewer. The represented participants are positioned as objects of contemplation (Kress \& van Leeuwen, 2006). However, there is a high degree of interaction between Svenn and the children. Again, the two children are gazing at him. This interaction shows that they are very interested in finding out what Svenn is looking for. The verbal text, as described above, also confirms this engagement, when it says that the children see that Svenn is crying, and that they decide to help him.

This image also establishes relationships between the represented participants and the reader in terms of what the image and the verbal text communicate. The proximity between Svenn and the children denotes a personal relationship between them. The visual resources, such as the kneeling of the children and their body language, also allow the reader to understand the power dynamics among the participants. In this case, the fact that the children are kneeling and in proximity to Svenn, may communicate a need for contact and closeness.

Spread 9 - Svenn's encounter with a flower vase and a pink basin
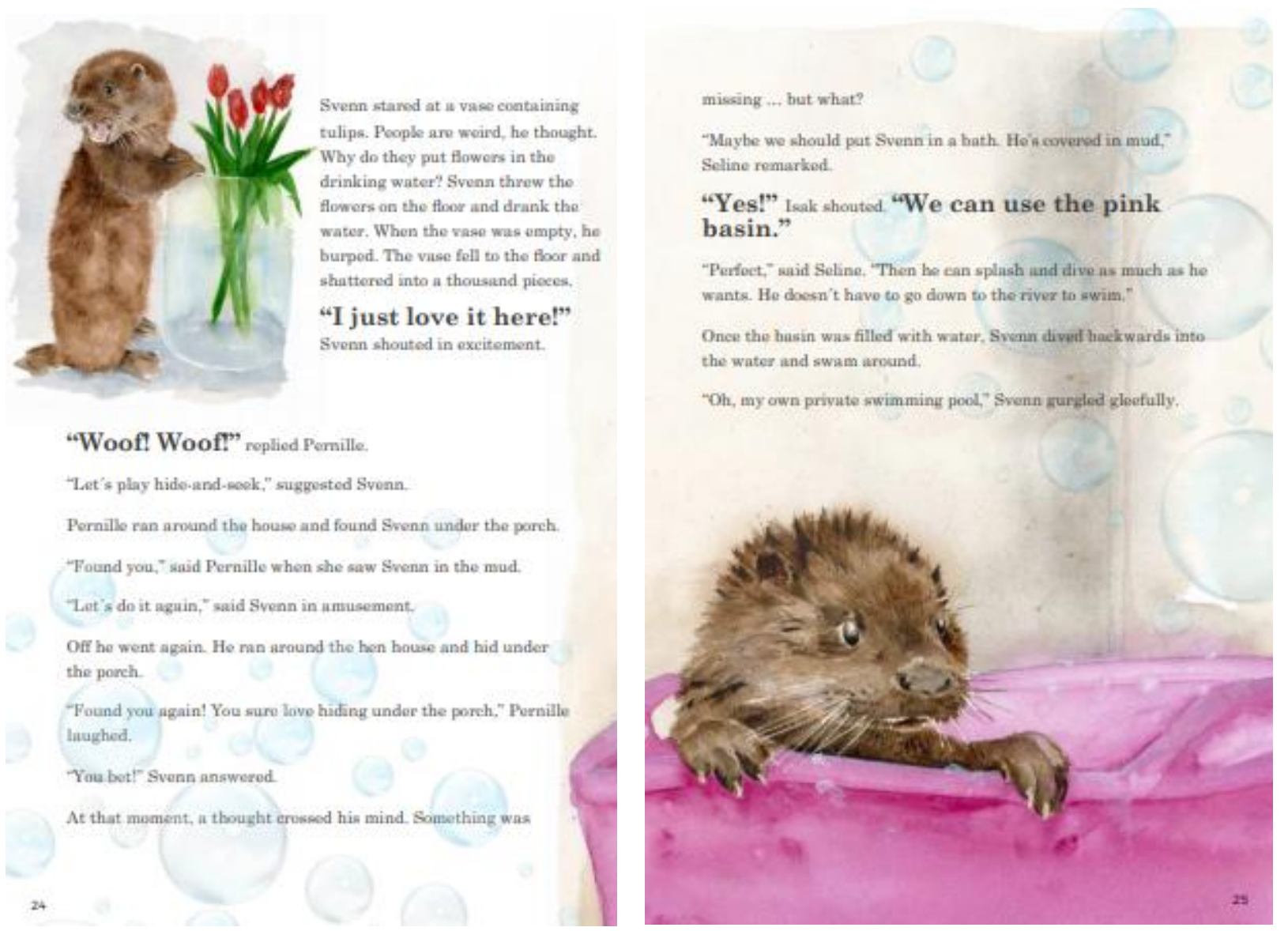

\section{Representation}

Another aspect of representation is the action process. In spread nine, the action process is not aimed at any participant or object. However, both participation and action take place. In the spread, this action process occurs involving only one participant and one vector. In the spread, the action performed involves only Svenn and the vector is represented by the body orientation of the participant and his physical interaction with nearby objects, which in this case are the flower vase and the pink basin. According to the text, there are other participants involved such as Pernille and Isak. However, the main visual focus is Svenn and his relationship with objects. In the image, both the vase and the basin work as mediating instruments in social negotiation activities and not as participants affected by any action. In other words, the instruments help negotiate meaning with the environment in which Svenn is now involved. For instance, Svenn interprets the vase as being a device to drink water and the basin as a private swimming pool. In 
addition, these instruments represent new sources of information about the context and about their relationship with the participant.

By choosing to focus only on Svenn and his relationship with household objects, the illustrator is able to highlight for the reader the social system that is developed in such a household; thus, assigning an image of safety and pleasure. It is worth noting that this interpretation is just one among many, but we want to highlight that the choice to represent certain elements in the image with a focus on its parts, or on its whole, generally reflects the objectives of those who build images and text, and produce certain effects on those who consume them. By embracing the context in which images and texts are produced and consumed, we can have a better-informed idea of possible interpretations.

Interaction

The images in spread nine, in addition to building representations, also establish relationships between the represented participant and the reader. Such relationships can be achieved through different visual aids, one of them being 'contact'. When talking about contact, we are referring to the gaze between the participant represented in the images and the reader. This contact, or relationship between the participant and the reader, can be personal or impersonal. In spread nine, the relationship is impersonal since the represented participant - Svenn - does not establish a direct gaze with the reader. He is portrayed in the image for the observation of the reader, and it is up to the reader to determine what is happening to Svenn in each one of the images. In this case, it would be to figure out whether he is having fun or being curious.

Spread 11 - Svenn's encounter with the toilet

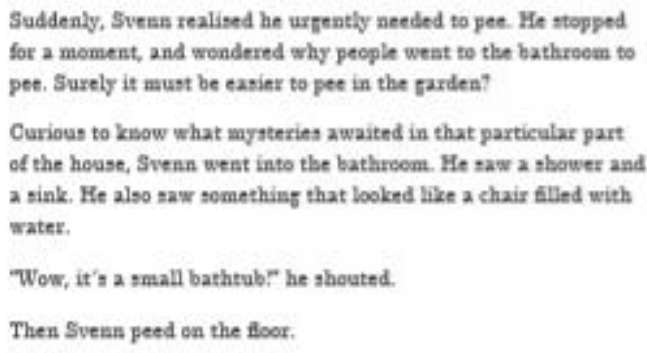

Suddenly, Svens realised he urfently needed to pee. He stopped for a moment, and wondered why people weat to the bathroem to pee. Surely it must be easier to pee in the farden?

Curious to ksow what mysteries awaited in that particular part of the house, Svenn went into the bathreom. He saw a sbower and a sink. He also saw semething that looked like a chair fllied with water.

"Wow, it's a small bathtub?" he shouted.

Then Svean peed on the floor.

Tinished" he shouted. Then he climbed onto the seat of the water-filled chair and plunged into the water, splashing it all the way up to the celling.

"I love swimming!" be cried out in amusement.

"Tm hungry" Svenn screamed while swimming in the toilet. "Pernille, can you get me some foed? I wast cales and ice cream",

"Svenn, that's 2 toilet:" Pernille barked.

Tou can't swim in it! ?

Go and hide in my bastbet before you get up to any mare mischief."

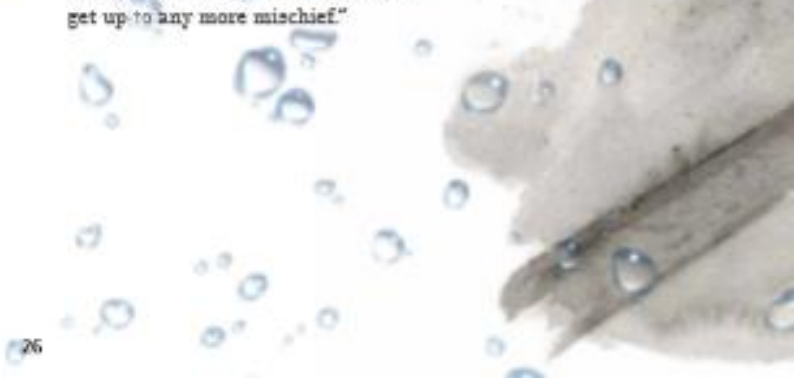

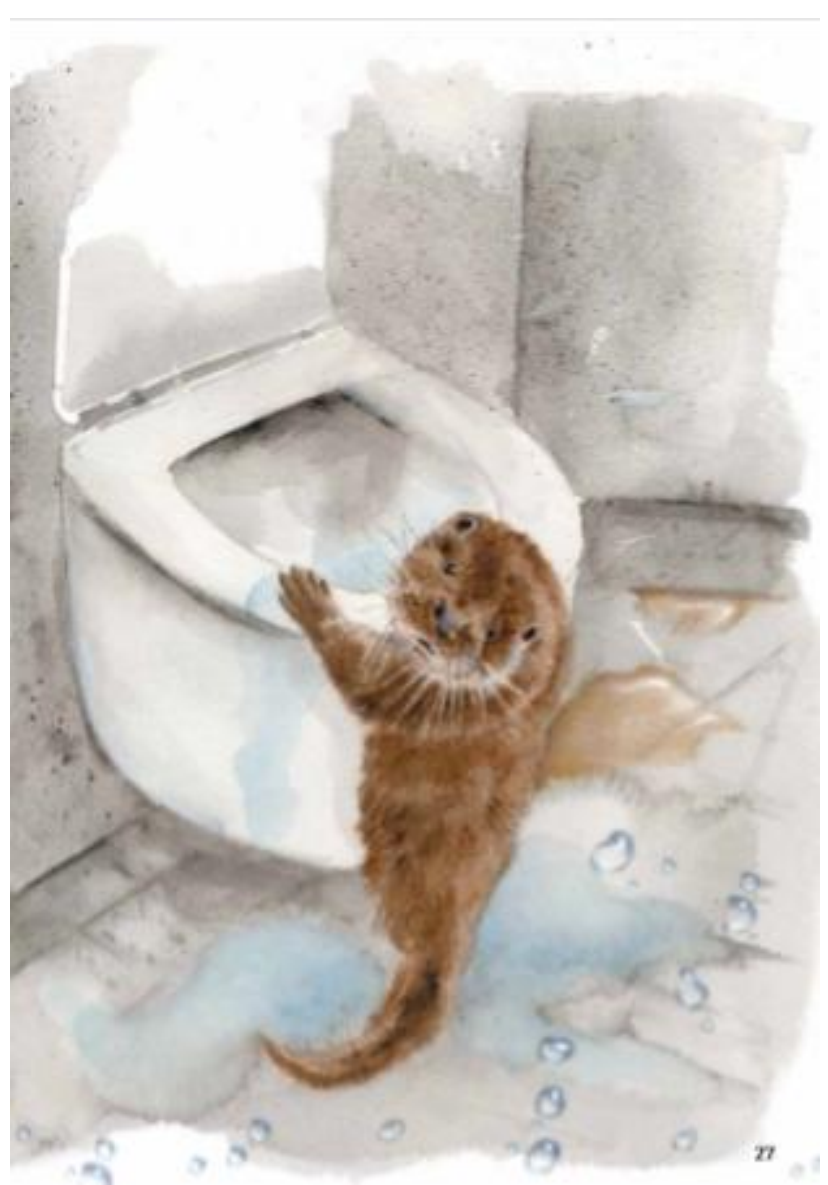

\section{Representation}

In spread eleven, as in spread nine, the action process is also not targeted at any participant or object. Nonetheless, both participation and action occur. The image involves Svenn and the action is performed by the body orientation of the participant; specifically, Svenn standing next to the toilet, with his hand gripping the toilet bowl. Even though, as in spread nine, there are other participants involved in the story, who are identified through the verbal language, the main visual focus is Svenn in his interaction with the toilet. It is worth noting that the illustration, in this spread, adds extra value to the overall representation of the experience of the participant. For instance, the toilet is represented with splashing water and water bubbles surrounding it, which gives to the image an added sense of playfulness. It is, therefore, a symbolic process. To put it another way, it is an image effect that adds symbolism to the representation, similar to the effect of using metaphors and analogies in verbal language. 
The image in this particular spread helps us expand the written story; particularly, the way Svenn is processing the information related to his surroundings. It seems relevant to comment that the role of images, among others, is to help the reader establish the necessary connection between information modes. In this case, they help the reader make the connection between the verbal language and the image, and to create meaning by moving from one mode to the other. As commented previously, images and text are interpreted in a way that creates effects (e.g., emotional) on those who consume those modes of information - either being the context in which narratives occur or the interpretation gathered by the reader.

Interaction

In terms of interaction, spread eleven allows for the further development of the relationship between the participant and the reader. Just as in spread nine, this relationship is achieved through 'contact'. In this case, the relationship between the participant and the reader is personal. Svenn is represented with his gaze focused directly at the reader. By having the participant appear to be looking directly at the reader, Svenn is creating a demand relationship. That is, the participant's look suggests that he is asking for something, such as compassion. This request for compassion can be inferred by the text as a whole. For example, Svenn interprets the toilet bowl as a small bathtub, a place to swim. However, he is later scolded by Permille, who tells him to go and hide before he gets into more mischief.

Multimodal orchestration

Finally, the analysis of multimodal orquestration allows us to describe the interplay of the elements represented in the image, which consists of both the image and the verbal text. From our analysis above, it follows that the images and verbal text support and enrich each other in the three spreads. Firstly, the images show Svenn in movement. This information is elaborated on by the verbal text, as it says that Svenn has a stomachache, and that he tries to hide in the grass when he hears the humans walking nearby. Secondly, the images depict Svenn's feelings and emotions, which are elaborated on by the verbal text, too. Svenn tries to swim in the toilet and gets confused when he sees that humans put flowers in the flower vase. Thirdly, we only know that Pernilla is present in the spreads because the verbal text gives us this detail. She is never visually depicted in the spreads. As such, the visual images and the verbal text in combination play a key role in contributing to depicting actions, events and emotions in the picturebook.

\section{DiSCUSSION AND PEDAGOGICAL IMPLICATIONS}

\section{A. The Representation of Svenn in the Children's Picturebook}

In this article, we sought to introduce basic concepts of Visual Grammar with a view to spreading this analytic approach and its categories in ELT, using picturebooks. Our intention was to add to the discussion of the value that texts composed of images can perform in addition to verbal language in language education. In order to analyze and discuss the value of picturebooks, and its implications for ELT, we explored categories in a holistic way as visualized within the NI approach, an approach in which narratives are framed within sociocultural perspectives, in terms of representation, language, and communication. Therefore, three categories were considered within the framework of multimodality: representation, interaction, and multimodal orchestration.

From the point of view of representation, the resources of an image allow us, among other things, to represent participants while involved in actions and events. For instance, Svenn's feelings and emotions are the central focus in the picturebook; those feelings and emotions manifest themselves in relation to others and in the new environment which he is part of. The value of this representation in the book lies in the importance of highlighting and understanding social systems, and the role of participants, their characteristics, identity, feelings or any other special attribute.

As for the function of interaction, typical features such as gaze are adopted to describe the type of relationship developed between the represented participants and the reader. By interacting with picturebooks, we can denote different degrees of interpellation between the reader and visual literacies. Also, the reader can sympathize with the participant (Svenn) in his discovery of objects and becoming familiar with his surroundings. Moreover, the reader is given an opportunity to react to some events in the story, e.g., to show compassion towards Svenn when Svenn gets confused.

Finally, multimodal orchestration allows us to gain insight into the value of presenting images and verbal text together. What do images show that the verbal text cannot tell us? For instance, why did the illustrator opt to depict Pernilla verbally and not visually? In other words, multimodal orchestration can increase our awareness of how the interplay of images and verbal text create depictions of situations in the picturebook.

\section{B. The Book Svenn the Otter and the Magic Rock in ELT}

The framework of multimodality, combined with an approach to understanding the human use of narratives for meaning-making of the world, can, in our view, enrich the work of ELT classrooms. Based on our discussion, we consider that visual literacy - images and text - can be organized around some multimodal activities within the English language classroom. Some activities are as follows:

Context for meaning making through picturebooks: Different cultural conventions can be discussed, analyzed, or interpreted. Visual and semiotic resources with texts can help assist language learners to reflect on their own narration of the text, by incorporating their knowledge of the target language, their own home language, and their cultural background. For instance, we can encourage children to empathize with the characters in the story by reading visuals. 
Teachers can point to images and ask children what in the images or in the verbal text is familiar or foreign to them. Teachers can direct their attention to visual or semiotic cues that can help children understand the context and interpret the actions in the story, in their own words. Context can help deepen understanding of specific situations and can impact what children learn in the classroom in the long run.

Interaction and relationship with others for meaning making: Images and verbal language can help readers understand different perspectives of participants of picturebooks and how they interact with objects and other participants. Equally, visual literacy can help readers understand better how they feel, based on what is illustrated in picturebooks. For instance, ELT learners can describe their feelings, supported by their knowledge of the target language, to make meaning of the emotions being portrayed in the story, based on their own knowledge of the world in a particular context. Language use, and its multiple variations (e.g., verbal, visual), is important for language learners to acquire abstract concepts such as emotional categories. For instance, teachers can help children understand the participants and their emotions from different perspectives. How do they think Svenn feels in his new home? How do they feel about seeing an otter live with people?

Verbal language for meaning making: Images accompanied by verbal text can help language learners understand the organization of the printed word in picturebooks. Each community or social group has its own written language conventions, or grammar conventions. The verbal language can help ELT learners understand how language varies according to context, and how language is organized in order to meet specific purposes and specific audiences. For instance, teachers can help children become aware of different elements in the text that can help them build meaning. Teachers can point to linguistic grammar conventions that children are familiar with, and they can use those conventions to either convey or retell Svenn's actions - or feelings - in the story.

It is important to note that these are some activities that can be implemented or considered in ELT using this picturebook, based on the spreads analyzed and discussed. More activities can be developed by using the whole book, such as addressing other visual metalanguage cues for meaning making; namely, color or framing. However, we hope that the analysis, and the sample activities, suggested for use in ELT, provide a comprehensive account of the potential that visual literacy, within multimodality, can have in language teaching. Specifically, they can support learners' conceptual knowledge of language, in its different representations, and support learners' abstract development of concepts related to emotions and cultural cues.

\section{SUMMARY AND CONCLUSION}

In this paper, the researchers have presented the children's picturebook Svenn the Otter and the Magic Rock, and analyzed three significant spreads. Our aim was to gain insight into the sociocultural environment where Svenn - along with other characters - is depicted in the picturebook. Moreover, we have provided a short discussion of how the picturebook may be used in ELT. Our work has limitations, as it did not cover all the categories within interaction (i.e., social distance and point of view) (Kress \& van Leeuwen, 2006). In addition, we did not take into account the analysis of compositional meaning, i.e., information values, framing and salience (Kress \& van Leeuwen, 2006). Again, we aimed to make this text as reader-friendly and practical as possible for ELT classroom teachers. Further research could develop a more detailed analysis of the book in terms of these categories.

Another aspect for further research is the availability of additional resources related to Svenn, such as the YouTube channel, Instagram and Facebook accounts, as well as the TV series, all of which depict Svenn in different ways. It would be interesting to do some type of classroom research, to explore how learners and teachers use such available resources. We posit that critical issues such as climate change, immigration, and the interplay between nature and humans could be addressed on the basis of those resources.

Finally, we hope that our paper can add to the discussion of the value of picturebooks in ELT, and that ELT classroom teachers find it both practical and useful. We believe that multimodal texts can be an asset in foreign language education, and picturebooks can be a great starting point for meaningful language work.

\section{ACKNOWLEDGMENTS}

The authors wish to thank Espen Villseth and Anita Sletten for providing us with the three spreads which we used in the present paper.

\section{REFERENCES}

[1] Donaghy, K \& Xerri, D. (2017). The Image in English Language Teaching. Floriana: Gutenberg Press.

[2] Ellis, G., \& Brewster, J. (2014). Tell it again!: the storytelling handbook for primary english language teachers. London: British Council.

[3] Freire, M. M. (2020). Transmedia Storytelling: from Convergence to Transliteracy. DELTA: Documentação de Estudos em Lingüística Teórica e Aplicada, 36(3). DOI: https://doi.org/10.1590/1678-460x2020360309.

[4] Fuchs, C., Hauck, M., \& Müller-Hartmann, A. (2012). Promoting learner autonomy through multiliteracy skills development in cross-institutional exchanges. Language Learning \& Technology, 16(3), 82-102.

[5] Gomez, M. N. (2020). The value of feedback in translanguaging: Students' insights from an English language course at Londrina State University. Revista X, 15(1), 115-135. DOI: http://dx.doi.org/10.5380/rvx.v15i1.69968. 
[6] Halliday, M.A.K., \& Hasan, R. (1985). Language, context and text: Aspects of language from a social semiotic perspective. Oxford: Oxford University Press.

[7] Halliday, M. A. K. (1978). Language as social semiotic. The social interpretation of language and meaning. London: Edward Arnold.

[8] Jakobsen, I. K. (2019). Inspired by image: A multimodal analysis of 10th grade English school-leaving written examinations set in Norway (2014-2018). Acta Didactica Norge, 13(1), 1-27. DOI: https://doi.org/10.5617/adno.6248.

[9] Jewitt, C., Bezemer, J., \& O'Halloran, K. L. (2016). Introducing Multimodality. London: Routledge.

[10] Koss, M. D. (2015). Diversity in contemporary picturebooks: A content analysis. Journal of Children's Literature, 41(1), 32.

[11] Kress, G., \& van Leeuwen, T. (2006). Reading images: The grammar of visual design. New York: Routledge.

[12] Lehtonen, M. (2000). The cultural analysis of texts. London: Sage.

[13] Lucarevschi, C. R. (2016). The role of storytelling on language learning: A literature review. Working Papers of the Linguistics Circle, 26(1), 24-44.

[14] Lund, R. (2016). Searching for the Indigenous: Urfolk i engelskverket Searching. In N. Askeland \& B. Aamotsbakken (Eds.), Folk uten land? A gi stemme og status til urfolk og nasjonale minorieter. Kristiansand: Portal Akademisk.

[15] Maager $\varnothing$, E., \& Øines, M. (2019). Hvordan lages barn? Bildebøker for barn om hvordan barn blir til - How to make children? Picture books for children about how to make a baby. Sakprosa 11(3), 1-32. DOI: https://doi.org/10.5617/sakprosa.6549.

[16] Maager $\varnothing$, E. \& Guri L. Ø. (2017). What a girl! Fighting gentleness in the picture book world. An analysis of the Norwegian picture book What a Girl! by Gro Dahle and Svein Nyhus. Children's Literature in Education, 48, 169-190. Heidelberg \& New York: Springer Press. DOI: https://doi.org/10.1007/s10583-016-9276-4.

[17] Maager $\varnothing$, E., \& Tønnessen, E. S. (2014). Multimodal tekstkompetanse. Kristiansand: Portal Akademisk.

[18] Mateas, M., \& Sengers, P. (Eds.). (2003). Narrative intelligence. Amsterdam: John Benjamins Publishing Company.

[19] Mourão, S. (2017). Picturebooks in instructed foreign language learning contexts. In C. Beauvais \& M. Nikolajeva (Eds.) The Edinburgh Companion to Children's Literature. Edinburgh: Edinburgh University Press.

[20] Painter, C., Martin, J. R. \& Unsworth, L. (2013). Reading visual narratives. Image analysis of children's picture books. Sheffield: Equinox Publishing Ltd.

[21] Pishghadam, R., Golparvar, E., Khajavi, G. H., \& Iranrad, E. (2011). Narrative intelligence and pedagogical success in English. Brazilian English Language Teaching Journal, 2(2), 178-189.

[22] Stafford, T. (2010). Teaching visual literacy in the primary classroom: comic books, film, television and picture narratives. London: Routledge.

[23] Skulstad, A. S. (2018). Multimodality. In A.-B. Fenner \& A. S. Skulstad (Eds.), Teaching English in the 21st Century: Central Issues in English Didactics. Bergen: Fagbokforlaget.

[24] van Leeuwen, T. (2005). Introducing social semiotics. London: Routledge.

[25] Song, H. (2013). Deconstruction of cultural dominance in Korean EFL textbooks. Intercultural Education, 24(4), $382-390$.

[26] Villseth, E. \& Sletten, A. (2020). Svenn the otter and the magic rock. Oslo: Nordic Wild.

[27] Waallann-Brown, C., \& Habegger-Conti, J. L. (2017). Visual representations of indigenous cultures in Norwegian EFL textbooks. Nordic Journal of Modern Language Methodology, 5(1), 16-34. DOI: https://doi.org/10.46364/njmlm.v5i1.369.

Nahúm M. Tórrez is a PhD candidate in ELT at the University of South-Eastern Norway. His main research interests include ELT textbooks, children's picture books and Digital Storytelling. He is also a lecturer at Tranby middle school in Lier, Norway. Email: nahum.m.torrez@usn.no,nahtorrez@gmail.com

Marjorie N. Gómez is an Associate Professor in ELT at Universidad Nacional Autónoma de Nicaragua. She holds a PhD in Linguistics from Londrina State University in Brazil. Her main research interests include translaguaging practices and Multicultural Education.Email: marjorie.gomez@unan.edu.ni,marjoriegt@gmail.com 